\title{
Analysis of Engineering Student Data in Online Higher Education During the COVID-19 Pandemic
}

\author{
https://doi.org/10.3991/ijep.v11i6.23259 \\ Zoe Kanetaki ${ }^{(\varpi)}$, Constantinos Stergiou, Georgios Bekas, Christos Troussas, \\ Cleo Sgouropoulou \\ University of West Attica, Egaleo, Greece \\ zoekanet@uniwa.gr
}

\begin{abstract}
The COVID-19 pandemic has challenged many educational institutions around the world in 2020 and 2021 as traditional education has been interrupted to prevent the spread of the virus. This forced the transition from traditional education to fully distance learning environments for all levels of education. The widespread adoption of distance learning has led instructors to form new digital learning environments and methods. In response to this unexpected situation, data regarding engineering students and their interaction with the learning environment was accumulated and processed, generating a matrix of $129 \times$ 165 variables. The motivation for this research is to identify new variables that impact student performance during the disorientation of the educational process due to the COVID-19 pandemic. Statistical analysis was performed and discussed in this paper including correlation analysis, factor analysis, and clustering. Reliability analysis was also performed and ANOVA (analysis of variance) was applied to clusters. The novelty of this work is to use student performance data and statistical analysis of online surveys to reveal patterns that can help reduce dropout rates and transform the educational process, under extenuating and imposed distance learning circumstances. A major finding is that by applying innovative teaching methods, thereby meeting the challenge of an imposed distance learning environment, students' spatial conceptions improve, overcoming the absence of a physical learning space. Deep insights for individual students were discovered, as well as significant relationships between students' transition from secondary to higher education and their understanding of geometric features. Evidence of the effectiveness of the online learning framework that was integrated showed that it positively influenced students' learning styles.
\end{abstract}

Keywords - data analysis, CAD, COVID-19, online learning, statistical survey, engineering education

\section{$1 \quad$ Introduction}

The effects of the COVID-19 pandemic became apparent in February 2020 in Greece. The closure of educational institutions around the world led to the creation of emergency distance learning environments [1-3] to replace face-to-face learning. The 
pandemic caused the largest disruption to educational institutions in history, affecting $94 \%$ of the global student population ${ }^{1}$.

High schools and universities around the world have responded to this crisis by offering synchronous and asynchronous course learning in the second quarter of 2020. The reduced number of COVID-19 cases in Greece allowed students to take the Greek university entrance exam in physical classrooms, after taking three months of online courses during lock-in in their senior year of high school.

On the other hand, engineering needs have stimulated innovative learning methods at all levels of the education sector. New parameters are involved in the educational process, for example digital platforms, while students follow courses individually, on a common virtual learning environment.

Retention of students until graduation is a recurring problem in higher education [3]. During their first year of study, the majority of students drop out, as shown in the literature [4]. The observed student anxiety, as a result of the disruption caused by COVID19 in the educational community [5], led to the implementation of immediate curriculum reform using pedagogical tools that would encourage motivation, decrease classroom fatigue, promote new knowledge in an "attractive" learning environment, provide asynchronous support via familiar social networks.

The results of this research can determine future trends in the educational community, a process that is of great importance to the research community [6]. By revealing patterns in the data analysis, the information gained can be transformed into a learning structure that can be used in other cases [7].

Online education, which has taken hold in higher education institutions around the world, has provided an excellent opportunity to acquire electronic data and monitor students' academic performance. The novelty of this research is to highlight data patterns and reveal valuable information about student engagement, assignments, and quiz and final exam scores that were obtained through the online platform via activity reports. Online surveys could be easily launched and the data obtained, merged with the platform reports during lock-in, allowed the vast majority of students to participate in this research, thus providing valuable information. It should be noted that this study describes new factors that may affect student performance in virtual learning environments. Because pandemic restrictions, as applied to educational systems, are fairly new, fully virtual learning environments, providing data on students under these imposed conditions, have not yet been evaluated. In the meantime, new factors are revealed with high levels of importance for students' academic performance in this new imposed virtual classroom. In addition, during the pandemic, the transition of students from high school to university in terms of performance has been re-examined as a sequence of knowledge under new circumstances. To our knowledge, such an analysis has not yet been conducted.

The remainder of this paper is organized as follows. Section 2 presents a review of the literature. Section 3 describes the research methodology. Section 4 presents the statistical analysis and discussion. Finally, Section 5 presents the paper's conclusions and recommendations for future research steps.

\footnotetext{
${ }^{1}$ Under UNICEF's policy brief from August 2020
} 


\section{$2 \quad$ Related work}

Monitoring student progress in online higher education courses has been the subject of new research $[8,9]$, but primarily in the context of exclusively face-to-face or online teaching environments.

One of the most significant roles of data analytics is to provide information about the students' performance in different stages: data can be obtained in several custom periods, during the whole online curriculum program, but also about their future performance by predicting their academic achievements, in terms of successfully obtaining the learning outcomes. In the latter, analytics can serve beneficially to learners that may need supplementary support or assistance during a critical assignment of the online curriculum [10].

Some of the techniques involved in learning analytics are statistical tests, predictive/explanatory models and visualization of the data [11]. The results of analysis can then lead the parties involved (administrators, educators, learners) to take action and reform a course. Although there is no standardized technique for how to use and apply data analysis, there are several ways in use for various scenarios. In [12], the authors conclude to three distinctive themes in learning analytics' implementation. The first stage contextualizes the development of predicators and indicators for several factors (learner performance, self-learning skills, engagement). The second is regarding the interpretation of data from visualizations and the conversation on the interpreted data. The final stage is about implementing the ideas from the interpretation onto the actual learning environment. The lack of an established learning analytics technique is often a challenge to institutes that consider adopting analytics [12].

There is a considerable number of researchers and studies regarding learning analytics and their implementation on higher education. In [13], the authors have performed some categorization of the research methods used in these studies. Qualitative evaluation, quantitative measures of use and attendance, differentiation between groups of students, differentiation between learning goals, data consolidation, and efficacy were explored in this study. Some of the tools that provide data for the above indicators are surveys, observations, students' class attendance, log files, eye tracking, group interviews and examination grades. These tools provide data that intend to mark an indicator that needs to be improved.

Another interesting research [14] examines the impact of statistical analysis and data mining has on adaptive learning. The results show that the learning process is affected in four critical areas: pedagogical difficulties, learning contextualization, networked learning, and educational resource management.

Another research [15] that includes important information about learning analytics' role is the method of implementing data which consists of social network analysis, semantic analysis, visual data analysis, and educational data extraction and mining. Learning analytics implementation presents a number of challenges on different levels including obtaining and analysing data, connecting the process to learning science and learning all those skills that are needed in order to reap the benefits of the analysis [10].

In [16], focus is brought upon objectives, methods, contexts, subjects, tasks, data gathering, and analysis methodology. The learning environment in this case consisted 
of students from computer science courses. While implementing learning analytics, case studies, survey research, constructive research, the experimental study provided useful data. Most data came from students during the time they were doing research. Automated data collection logs were created to provide learner records as they performed different tasks. Descriptive and inferential statistics were then employed to provide useful insights of that data.

Big data and learning analytics are a developing field in higher education. Examining the learning process and improving it requires two types of data: learner's data and content data. Using these two types the learning analytics' implementation process can alter a course to attain better results. On a larger scale, using big data from whole institutions could reform education in its essence providing personalized learning resources and higher course completion rates [17].

Data processing by a statistical analysis, produces outcomes that can benefit students and educators and can lead to a more effective distance learning environment, not only during COVID-19 circumstances, but in all future remote teaching systems. Although the majority of existing research on undergraduate first-year engineering programs reduces the importance of high school courses in preparing and orienting students to college-level studies, [18], still, researches focus on analysing correlations of first year academic achievements with previous high school performance, in related modules who present a content sequel [20].

Multiple studies focusing on the evaluation of E-learning modules prior to the COVID-19 pandemic [21, 22] identify constructs (factors) that can be interpreted as questions on an extensive survey. Researchers $[13,22]$ identified factors that have a favourable impact on E-learner satisfaction, including information quality, system quality, diversity in assessment and learner perception, and engagement with others. Multiple publications examine technical difficulties, stating that stronger the learning effects can be achieved by the high quality and reliability of the technology used. [22, 23].

\section{$3 \quad$ Research methodology}

The present research is based on a case study of a first semester mechanical engineering CAD module at the Department of Mechanical Engineering, School of Engineering, at the Western University, Attica, Athens, Greece. Linking high school performance to first semester academic performance under pandemic circumstances presents a new reality that lends itself to a sequence in teaching modes: students' final year of high school that is expressed by their performance in university entrance exams and their first semester performance in a specific online module $[18,19]$.

\subsection{Objectives}

The purpose of this research is to reveal what factors lead to better academic outcomes for first-year university students in mechanical drafting CAD under the circumstances of COVID-19. Students are enrolled in the first semester Mechanical Drafting 
CAD I course, a three-hour task-based, mindset-based laboratory learning course, at West Attics University. Due to the transition imposed by the focus from face-to-face learning to a virtual learning environment, the factors that affect student performance have changed. Student engagement across online platforms can be expressed through "insights" tools in the platforms that provide information about students' digital activity during a specific time period.

\subsection{Form of training and final examination}

The form of training that was applied during the semester was 3-hour synchronous online meetings scheduled in MS Teams. MS Teams was used for both synchronous and asynchronous learning, leaving out the LMS (Moodle) used in typical classrooms to support the module. Integration of specific LMS functionality into a single learning platform (MS Teams) was used to avoid disruption from two different learning systems.

The teaching material that has been approved by the Department of Mechanical engineering has been reformed by the coordinator in order to meet the needs of the physical absence of the instructor. Blackboard sketching demonstration has been substituted by free hand sketching audioless videos visualisation, permitting the instructor to lecture while playing and pausing videos by screen sharing. A typical sketching video can be watched in https://www.youtube.com/watch? $\mathrm{v}=18 \mathrm{LVvr} 5 \mathrm{uIz0}$ CAD drawings and Autocad commands were demonstrated synchronously by screen sharing, while 3-Dimentional objects were modelled in Autodesk Inventor by the coordinator, recorded as a video uploaded on the supporting You Tube channel, displayed and discussed with the students in share screen mode.

The software used by the coordinator in order to create assignments and model 3-Dimentional objects was Autodesk Inventor Pro 2020 and Autodesk AutoCAD $2017^{3}$ for creating and displaying commands on 2-Dimensional drawings. Students were asked to download any educational version of Autodesk AutoCAD in order to perform their vector drawings. AutoCAD has been used as an electronic vector drawing tool, using coordinates, in its basic form, without loading the specific engineering plugins.

At the end of the module lectures, students should be able to represent in 2-Dimensional views a simple (basic) mechanical part, shown in a 3-Dimensional isometric view, by applying the rules of mechanical drawings (hidden edges, visible edges, view placement, top views, side views, sectional views etc.). A dwg ${ }^{4}$ file has been turned in and graded through a rubric which makes explicit the criteria of judging students mindson task. A total of 198 students' tests have been evaluated by this rubric, in order to eliminate subjective attitudes from the four instructors that performed the gradings.

\footnotetext{
${ }^{2}$ Educational version

${ }^{3}$ Educational version

${ }^{4}$ Autocad vector drawing
} 


\begin{tabular}{|c|c|c|c|c|}
\hline $\begin{array}{l}\text { GRADING RUBRIC FINALS } \\
\text { marking criteria }\end{array}$ & & & \multicolumn{2}{|c|}{100 points possible ${ }^{X}$} \\
\hline FRONT VIEW & & & & Weight $30 \%$ \\
\hline $\begin{array}{l}\text { Excellent } 10 \text { points } \\
\text { COMPLETED AND CORRECT }\end{array}$ & $\begin{array}{l}\text { Good } 7 \text { points } \\
\text { SOME EDGES ARE MISSING }\end{array}$ & $\begin{array}{l}\text { Fair } 4 \text { points } \\
\text { WRONG AND MISSING EDGES }\end{array}$ & $\begin{array}{l}\text { Poor } 0 \text { points } \\
\text { MISSING VIEW }\end{array}$ & \\
\hline SIDE VIEW & & & & Weight $20 \%$ \\
\hline $\begin{array}{l}\text { Excellent } 10 \text { points } \\
\text { COMPLETED AND CORRECT }\end{array}$ & $\begin{array}{l}\text { Good } 7 \text { points } \\
\text { SOME EDGES ARE MISSING }\end{array}$ & $\begin{array}{l}\text { Fair } 4 \text { points } \\
\text { WRONG AND MISSING EDGES }\end{array}$ & $\begin{array}{l}\text { Poor } 0 \text { points } \\
\text { MISSING VIEW }\end{array}$ & \\
\hline TOP VIEW & & & & Weight $20 \%$ \\
\hline $\begin{array}{l}\text { Excellent } 10 \text { points } \\
\text { COMPLETED AND CORRECT }\end{array}$ & $\begin{array}{l}\text { Good } 7 \text { points } \\
\text { SOME EDGES ARE MISSING }\end{array}$ & $\begin{array}{l}\text { Fair } 4 \text { points } \\
\text { SOME EDGES ARE MISSING }\end{array}$ & $\begin{array}{l}\text { Poor } 0 \text { points } \\
\text { MISSING VIEW }\end{array}$ & \\
\hline LAYERS AND UNETYPES & & & & Weight $10 \%$ \\
\hline $\begin{array}{l}\text { Excellent } 10 \text { points } \\
\text { UNES ACCORDING TO GIVEN LAYERS }\end{array}$ & $\begin{array}{l}\text { Good } 7 \text { points } \\
\text { WRONG UNETYPE SCALE }\end{array}$ & $\begin{array}{l}\text { Fair } 4 \text { points } \\
\text { UNES NOT ACCORDING TO LAYERS }\end{array}$ & $\begin{array}{l}\text { Poor } 0 \text { points } \\
\text { THE DRAWING Is } \\
\text { HAVE NOT BEEN }\end{array}$ & N LAYERS \\
\hline
\end{tabular}

Fig. 1. Scoring grid for the final exam

\subsection{Research sample}

The online module context was applied to 216 students in 11 online groups on the MS Teams platform, led by a group of 5 instructors $(\mathrm{N}=216)$, from October 2020 to January 2021. One of the five instructors coordinated the instructional materials, platform structure, and assignments for the 11 online groups. The coordinator also taught online courses in three MS Teams groups, along with the other four instructors. Each course group has been divided equally by the instructors and has 18 to 22 students, resulting in a teacher/student ratio of $1 / 22$. Students self-select into each group of their choice, with no prior knowledge requirements. The instructors are university professors, assistant professors, and have twenty years of experience in education, particularly in teaching DAC. The online courses were held in three-hour synchronous meetings.

190 students volunteered to participate in this research, $88 \%$ male and $12 \%$ female. The research sample included the first three levels of university education, in order to focus the research on the transition of first-year students from high school to entrance exams to the first semester at university, with a valid number of 165 participants $(\mathrm{n}=$ 165 ). In terms of age, $87 \%$ of participants were between 18 and 21 years old, $11 \%$ were between 22 and 25 years old, and the remaining 3\% were over 25 years old. $77 \%$ of students lived with their families, and 53\% lived in family households with 4 members. $63 \%$ of students took online courses in the same city, $35 \%$ in another city, and $2 \%$ in another country. $63 \%$ of the students were financed during their studies by their parents. $82 \%$ of students own their own computer or laptop, with fully functional camera and audio. $49 \%$ of students spend 2 to 3 hours per week on homework and $54 \%$ of students spend 3 to 4 hours.

The students who participated in this research meet the following characteristics:

- Attended online for at least 7 lectures.

- Uploaded their homework assignments.

- Attended during their first, second, and third year.

Therefore, the sample can be considered a representation of this sub-population of the total number of students. 
The available resources, associated with two online surveys, were classified into concepts and variables. The extracted data were merged from the following sources:

1. First Questionnaire (Pre-course):

The first online survey was launched during the first online course. The questions provided information about students' prior academic performance in high school, during the COVID-19 closing period, and specifically about their grades acquired on university entrance exams $[18,19,24]$. The sub-subjects include mathematics, physics, essay, chemistry...

2. Second Questionnaire (Post-course):

The second online questionnaire was launched in the 9th online lecture, including various aspects of the learning framework. It was shared with students during the 8 th out of 9 courses in the academic semester. The purpose of this survey was to assess students' impression immediately after the online module and just before the final exam, so that their attitude towards the course would not be affected by their grade.

3. Additional Students' Data

The above includes available resources, class group and instructor records and attendance lists, and general student characteristics, including type of high school, time of class (morning or afternoon class), number of instructors, instructor identification.

\subsection{Structure and concepts}

These two online surveys were merged and combined with test scores and homework results, introspection data, and student educational data with 129 variables.

The questions were introduced so that cross-referencing responses to different questions would provide additional information.

These online surveys consisted of 9 constructs applied to learners to test "system performance" in terms of student academic outcomes and sustainability during COVID-19 closure periods. The constructs were chosen to be consistent with previous evaluations of online learning that have been conducted $[22,25]$ and some during the COVID-19 pandemic period [20, 23]. Other objectives are to identify their attitude towards the learning framework, the level of understanding of the relationship between the assessments and future real-world mechanical engineering tasks [22].

- Student demographics: This construct includes gender, age, parents' educational background, travel time to the university, age, gender, activities and hobbies [22].

- The emotional state of the student during the pandemic containment period, and the impact on their academic progress, after having to take all courses online [20, 23].

- Technical difficulties [20, 23].

- Work on homework, including study time and homework results [20, 23].

- Quality of context and content [20,23]: Students evaluate the learning environment as it has been completely reformed from a Face-to-Face environment to a virtual classroom, including their attitudes towards innovative methods of object and task 
perception, asynchronous homework support, variety of tasks, modes of course content presentation, in terms of innovation and good practice. The innovation variable is revealed in this construct by questions that focus on the technological methods applied on this electronic module during the first semester of studies.

- Students move from the face-to-face to the distance learning environment $[20,23]$ : The survey questions may reveal hidden parameters expressing the level of difficulty students faced in their transition from high school to university education under the circumstances of COVID-19.

- Instructor effectiveness and social role: Students expressed positive or negative attitudes toward their instructor, the quality of their instruction, and their social role in the virtual classroom.

- Self-efficacy: This construct is referring on the prior level of knowledge, grades of entrance exams [19], computer and software skills [22], abilities in the use of social media [26].

- Sustainability of the online learning framework [27]: As the United Nations Sustainable Development Group notes in its August 2020 guidance note, strengthening education systems helps countries adapt to immediate challenges, such as reopening schools safely, while training them to deal with future crises. The purpose of this construct is to determine whether some of these learning styles can be applied in the future, under the following circumstances:

(a) A partial reopening where students will take modules in a "blended" learning environment during the post-lockout period [27].

(b) Return to the real classroom environment, through synchronous or asynchronous support, or even a virtual classroom running parallel to the real classroom.

(c) Adapt the content of the module in case of a future crisis.

\subsection{Discussion}

When applying the specific analysis methodology, several difficulties were noted, particularly during data collection. Initially, students were present online and it was difficult to find and engage them in the surveys. Two online surveys had to be launched (one before class and one after class) in order to capture the information in two stages. The first was for students' grades at the very beginning of their college experience, so that they would not be forgotten or misreported. The second was to be initiated at the time all online courses for the eleven class groups were given, but before the online final exam took place, to avoid being influenced by the online exam process and its degree of difficulty.

Because all participation in both surveys was identified by the student's matriculation number and was not anonymous, instructors had to convince students to report their truthful responses in order to cross-analyze survey responses with their grades. Motivating students to participate in both surveys by expressing their sincere attitude toward the learning strategy and its components was a great challenge for the instructors, but especially for the course coordinator. It turned out that due to the restrictions of COVID-19, the students were pre-motivated and more than willing to participate, especially in the second survey which was more demanding, with an average time of 
32 minutes to complete it. Both surveys had to be cross-checked to ensure that all students had participated in both online surveys to avoid missing values when transferring to SPSS. Students who missed one survey had to be screened during the week before the final exam and reminded to take the other survey. Merging the data from two online surveys, MS Teams insights, and additional information provided by the school's administration office to be analyzable took a great deal of effort to manage the totality of the acquired data.

The collected data was processed through statistical analysis, in order to present the factors that affect the learners' academic performance, expressed by their score on the final exam of the online module CAD I.

\section{$4 \quad$ Statistical analysis and discussion}

In this section, correlation analysis, factor analysis and cluster analysis are presented along with discussion on the results.

\subsection{Correlation analysis}

A correlation analysis has been performed in SPSS (Spearman's rank correlation coefficient) determining the correlation coefficients among the 85 ordinal variables of the questionnaire in order to understand the relationships linking them (Table 1). The Spearman's rank correlation coefficient has been used in similar studies [28, 29], and its purpose is to identify the level of association between two variables. It should be noted that the significance (2-tailded) of those correlations, expressed with a p-value after a Spearman's rho correlation analysis has to be below to 0.05 , in order to be statistically significant. In the following analysis, outcomes are proceeded by () stating values as (Correlation Coefficient, Sig. (2-tailed) drawn from the relevant SPSS output file. Leading zero has been suppressed.

Table 1. Correlation coefficients of significant value.

\begin{tabular}{|l|c|c|}
\hline & \multicolumn{2}{|c|}{ Grade Finals } \\
\hline CAD I enjoyable vs other labs & Correlation Coefficient & Significance (2-tailed) \\
\hline Insecure about online CAD I module & $.272^{* *}$ & 0.000 \\
\hline Comfortable for the finals CAD I & $.215^{* *}$ & 0.006 \\
\hline Study time (hours) per week & $.206^{* *}$ & 0.008 \\
\hline Studying during the week (day) & $.193^{*}$ & 0.013 \\
\hline Necessity of sketching & $.288^{* *}$ & 0.000 \\
\hline
\end{tabular}

In the following section, the most important outcomes of the analysis will be conferred, with regard to constructs, as representative fields of the research.

Students transition from high school to university during the COVID-19 pandemic. Students with higher grades in mathematics seem to have a better perception in 
3 dimensions as they fully perceive parts in assignments $\left(.226^{* *} .006\right)$ (see Figure 2, Table 2).

Students' grades in physics exams reveal a strong relation with their grade in the final CAD exam $(.307 * * .000)$ on the online CAD I module. The learners with higher grades in physics and CAD I module feel confident to succeed in a similar future task: $(.307 * * .000)(.265 * * .000)$ (see Figure 2$)$.

At this point, it can be assumed that the discipline of physics seems to be related to CAD I most probably due to dealing with vectors, which is a basic requirement when drawing engineering plans.

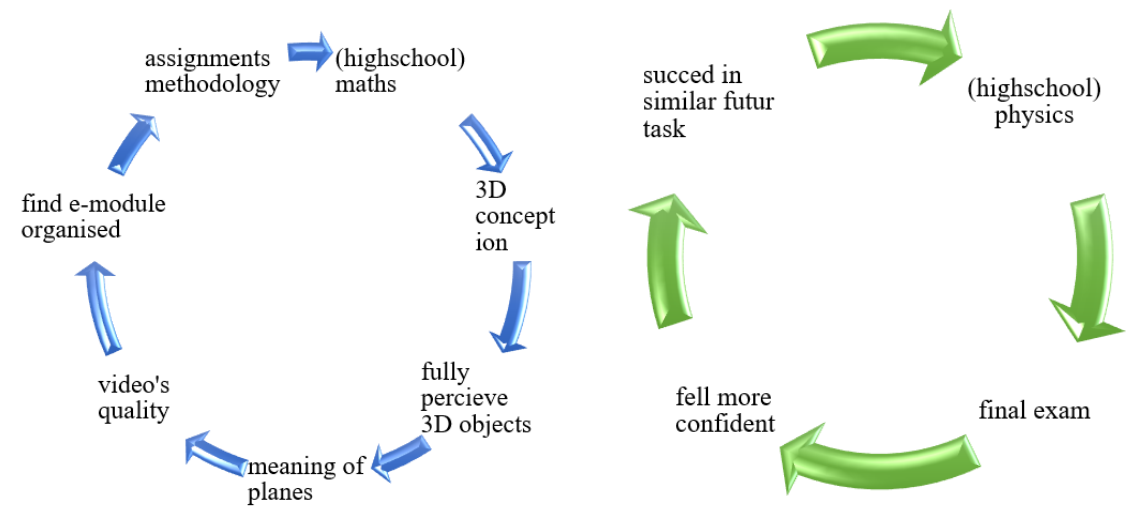

Fig. 2. Correlations flowchart. Examples of Mathematics and Physics

Table 2. Students' university entrance exams related to their first semester academic performance in the CAD I online module

\begin{tabular}{|c|c|c|c|c|c|}
\hline & & & MATHS & CHEMISTRY & PHYSICS \\
\hline \multirow{18}{*}{ 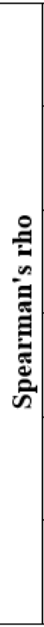 } & \multirow{3}{*}{$\begin{array}{l}\text { Object fully perceived in } \\
\text { tasks }\end{array}$} & $\mathrm{CC}^{* * *} *$ & $.226 * *$ & 0.118 & 0.117 \\
\hline & & Sig. (2-tailed) & 0.006 & 0.178 & 0.179 \\
\hline & & $\mathrm{N}$ & 149 & 132 & 133 \\
\hline & \multirow{3}{*}{$\begin{array}{l}\text { Likely to succeed in a } \\
\text { similar future task }\end{array}$} & $\mathrm{CC}^{* * * *}$ & 0.134 & $.191^{*}$ & $.265^{* *}$ \\
\hline & & Sig. (2-tailed) & 0.104 & 0.029 & 0.002 \\
\hline & & $\mathrm{N}$ & 149 & 132 & 133 \\
\hline & \multirow{3}{*}{$\begin{array}{l}\text { Grade in entrance exam } \\
\text { mathematics }\end{array}$} & $\mathrm{CC} * * *$ & 1 & 0.163 & $.325 * *$ \\
\hline & & Sig. (2-tailed) & & 0.061 & 0 \\
\hline & & $\mathrm{N}$ & 149 & 132 & 133 \\
\hline & \multirow{3}{*}{$\begin{array}{l}\text { Grade in entrance exam } \\
\text { dissertation }\end{array}$} & $\mathrm{CC}^{* * * *}$ & -0.114 & -0.062 & -0.114 \\
\hline & & Sig. (2-tailed) & 0.167 & 0.485 & 0.193 \\
\hline & & $\mathrm{N}$ & 148 & 131 & 132 \\
\hline & \multirow{3}{*}{$\begin{array}{l}\text { Grade in entrance exam } \\
\text { physics }\end{array}$} & $\mathrm{CC}^{* * * *}$ & $.325 * *$ & $.265^{* *}$ & 1 \\
\hline & & Sig. (2-tailed) & 0 & 0.002 & \\
\hline & & $\mathrm{N}$ & 133 & 132 & 133 \\
\hline & \multirow{3}{*}{ Grade finals CAD I } & $\mathrm{CC}^{* * *}$ & 0.1 & 0.048 & $.307 * *$ \\
\hline & & Sig. (2-tailed) & 0.225 & 0.588 & 0 \\
\hline & & $\mathrm{N}$ & 149 & 132 & 133 \\
\hline \multicolumn{6}{|c|}{$\begin{array}{l}* \text {. Correlation is significant at the } 0.05 \text { level (2-tailed). } \\
* * \text {. Correlation is significant at the } 0.01 \text { level ( } 2 \text {-tailed). } \\
* * * \text { Correlation coefficient }\end{array}$} \\
\hline
\end{tabular}


Affected by technical issues and insecurity (see Figure 2). The presence of technical issues highly affects the enjoyability of the online CAD I module $(.250 * * .001)$, and increases their sense of insecurity $\left(.317^{* *} .000\right)$ as well as their being uncomfortable for the final test $(.229 * * .003)$. Students resent draining data from their smartphone when downloading the support videos ${ }^{5}$ related to their assessments $(.280 .000)$.

The absence of bandwidth internet connection seems to have a negative effect on the enjoyability of the e-module as compared to other theoretical courses $\left(.238^{* *} .002\right)$ and therefore assumes an important subset under technical issues construct.

Affected by social distancing (see Figure 2). Students who sense a discomfort from social distancing, feel more uncomfortable for the final exams for all online courses. $(.214 * * .006)$ and specifically for online CAD I final test $\left(.688^{* *} .000\right)$ while they are also the ones who are more affected by technical issues $\left(.171^{*}\right)$. Being physically distant from their classmates has not been found to relate with the students' final grade $(.055$.484). It can be revealed though that social discomfort is related to feeling uncomfortable for the finals $\left(.214^{* *} .006\right)$

Enjoyability of the online learning framework (see Figure 2). Students that find online CAD I more enjoyable when compared to other modules are more satisfied with their assignment grades $\left(.338^{* *} .000\right)$ consider that the module is very well-organized $(.403 * * .000)$, and the tasks are very well assessed $\left(.308^{* *} .000\right)$. They also consider that the theoretical part of the lecture, the class notes and the quizzes contribute to accomplishing the assignments and to understanding the theory. (.268**.381**.243** $\left..252^{* *}\right)$ It can be shown at this point that "enjoyability" is perceived as a part of knowledge transmission, since the students who find the course enjoyable also assess well the variety of tasks, $\left(.326^{* *} .001\right)$, conceived essential geometric details like the meaning of planes $(.262 * * .001)$, rated highly the quality of videos concerning the assessment's methodology $(.407 * * .000)$ and the clearness of image and sound $\left(.275^{* *}\right.$ $.000)$. High-performance students find the online CAD I module more enjoyable than other online laboratory modules $\left(.272^{* *} .000\right)$, feel less insecure $\left(.215^{* *} .006\right)$ and more comfortable for the finals (.206 .008). The same students tend to spend more hours per day for studying $(.193 * .013)$, but work in a more systematic way $\left(.288^{* *} .000\right)$.

Familiarization with the learning platform. Students who got familiarized with MS Teams during the first week, highly evaluate the online CAD I in terms of organization, the assessment process of the tasks, the contribution of the class notes and quizzes, the variety of the tasks, the module's assistance on their conceiving the meaning of planes, and the presence of cutting planes. $(.379 * * .000)\left(.335^{* *} .000\right)\left(.368^{* *} .000\right)$ $(.331 * * .000)(.335 * * .000)(.303 * * .000)(.238 * * 000)$. They also fully perceive the objects presented in 3-dimentional views, evaluate highly the importance of $3 \mathrm{D}$ visualization videos, the You Tube channel videos in terms of the methodology, clearness of image and sound, and do not find the online course exhausting $\left(.234^{* *} .003\right)\left(.233^{* *}\right.$ $.003)\left(.336^{* *} .000\right)(.328 * * .000)(.383 * * .000)\left(.266^{* *} .000\right)$.

Familiarization to MS Teams platform has contributed scientifically to the understanding the teaching context in all its aspect.

\footnotetext{
${ }^{5}$ You Tube channel MCAD I
} 
MS Teams activity report. MS Teams Insights tool has been applied in order to determine the students' commitment on the CAD I module. An activity report ${ }^{6}$ has been extracted for each one of the 11 groups, in a custom period of 3 months. The xlsv file extracted has been processed with Microsoft excel by replacing all "V" symbols with " 1 ". The value number has been obtained by summing. Numbers range has found from $0-57$, determining 57 as the maximum value expressing students' involvement in the CAD I virtual module.

Students that feel insecure about the module did not conceive the meaning of planes and do not think they can accomplish similar tasks in the future $(.240 * * .002)(.279 * *$ $.000)$ they also did not evaluate well the online CAD I module and evidently their final exam grade was low.

Virtual classroom fatigue. Feeling exhausted from attending the online module is probably the reason students do not highly evaluate online CAD I (.482**.000). On the other hand, students who have highly evaluated the course $\left(.469^{* *} .000\right)$ and the variety of assignments $\left(.367^{* *} .000\right)$ consider it not exhaustive, feeling more satisfied with the module than with other online courses $\left(.475^{* *} .000\right)$.

Interactivity. Interactivity is a factor which determines students' satisfaction $\left(.396^{* *} .000\right)$ and preference to other online modules $\left(.478^{* *} .000\right)$. It is related to the familiarization to MS Teams platform $(.369 * * .000)$ and the level of organization of the teaching framework $(.460 * * .000)$ as well as how tasks are assessed $(.360 * * .000)$. Quizzes after each lecture increase the learning interactivity $\left(.352^{* *} .000\right)$. Students find the variety of assessments (quizzes, sketches, CAD drawings) interactive $(.510 * *$ $.000)$. Interactivity also contributes to a better conception of the meaning of planes $(.258 * * .000)$. High evaluation ratings $(.608 * * .000)$ of the module are related to the interactivity of the learning framework.

Understanding geometrical features. Understanding the meaning of planes, and the presence of cutting planes in isometric views has been researched through this analysis which revealed that distance learning through online platforms (MS Teams) contributed significantly to students' high grades $(.303 * * .000)(.294 * * .000)$ (see Table 3 ). The presence of cutting planes in isometric objects views helped conceiving the meaning of planes $(.355 * * .000)$. High correlation coefficients reveal implicit relations of those 2 critical parameters with the enjoyability of the course, the interactivity $\left(.258^{* *} .001\right)$, students' preference to other online modules, the degree of organization of the teaching content and the methodology presented on the module's YouTube Channel videos, the lack of fatigue $(.280 * * .000)$.

Cutting planes highlighted in blue "see Figure 3" is more related to the total grade which includes $30 \%$ from the weekly assignments turned in during the semester $\left(.220^{* *}\right)$ that the final grade $\left(.180^{*}\right)$. Younger students have a higher level of understanding on essential details of the tasks, such as the meaning of planes (-.176*) and have been familiarized to MS Teams sooner $\left(.207^{* *} 0.008\right)$ which implies that older students need more time to familiarize with the platform. Students that find online CAD I more enjoyable than other labs, are more satisfied versus other courses, got familiarized to MS Teams faster (.405** .000) (.530** .000), feel less insecure (.215** .006),

\footnotetext{
${ }^{6}$ Csv file
} 
more comfortable for the finals $\left(.225^{*} .004\right)$, less affected by technical issues $\left(.245^{* *}\right.$ $.002)$ and do not consider assignments to have a heavy load (.208**.007).

Table 3. Significant correlations with the conceptions of planes

\begin{tabular}{|c|c|c|c|}
\hline & \multicolumn{3}{|c|}{ Spearman's rho } \\
\hline & \multicolumn{3}{|c|}{ Conception of planes } \\
\hline & Correlation Coefficient & Significance (2-tailed) & $N$ \\
\hline Familiarised to MS Teams vs other modules & $.303 * *$ & 0.000 & 165 \\
\hline Satisfied vs other modules & $.224 * *$ & 0.004 & 165 \\
\hline Insecure about online CAD I & $.240 * *$ & 0.002 & 165 \\
\hline Comfortable for the finals CAD I & $.225^{* *}$ & 0.004 & 165 \\
\hline Well organised CAD I & $.268 * *$ & 0.001 & 165 \\
\hline How well tasks are assessed & $.313 * *$ & 0.000 & 165 \\
\hline Evaluate assignments variety & $.228 * *$ & 0.003 & 165 \\
\hline Necessity of sketching & $-.194 *$ & 0.012 & 165 \\
\hline Presence of cutting planes in 3-dimentional views & $.355^{* *}$ & 0.000 & 165 \\
\hline Object fully perceived in tasks & $.228^{* *}$ & 0.003 & 165 \\
\hline Quality of videos in assignments methodology & $.238 * *$ & 0.002 & 165 \\
\hline Classroom fatigue & $.280 * *$ & 0.000 & 165 \\
\hline Interactivity & $.258 * *$ & 0.001 & 165 \\
\hline Likely to succeed in a similar future task & $.489 * *$ & 0.000 & 165 \\
\hline Sustainability of the module's context & $.242 * *$ & 0.002 & 165 \\
\hline Overall evaluation CAD I & $.271^{* *}$ & 0.000 & 165 \\
\hline Grade finals CAD I & $.294 * *$ & 0.000 & 165 \\
\hline
\end{tabular}
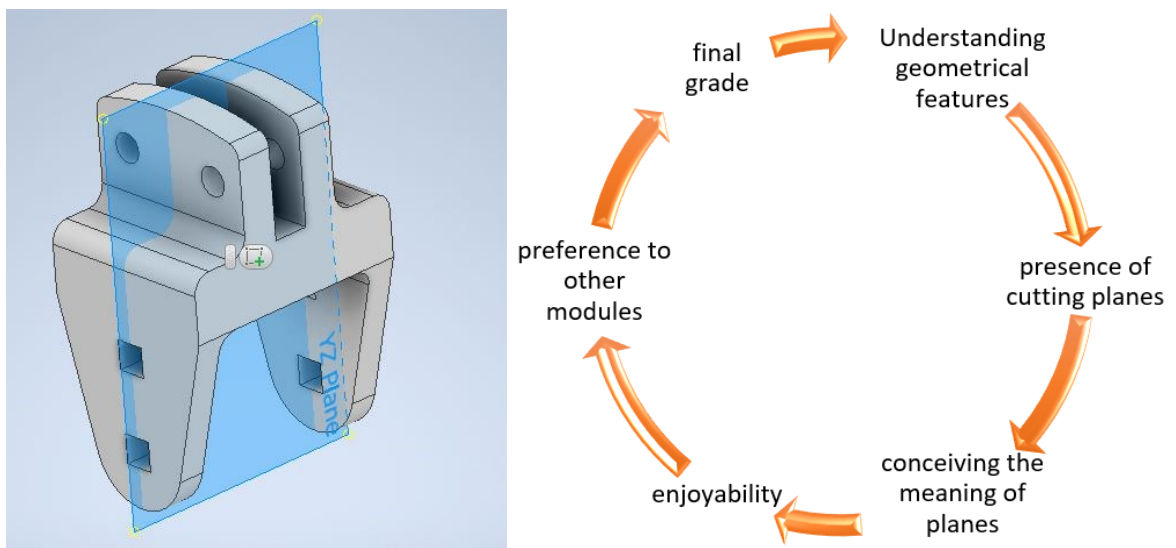

Fig. 3. Cutting planes highlighted in blue and Organigram on the base of geometric features

Students who quit sketching at an early stage, or perform it in more complicated parts, work directly on CAD as they have already managed to develop their 3-Dimensional conception. Surpassing this step diminishes their sense of insecurity about this 
module $(.234 * * .002)$. The necessity of sketching has a negative impact (-.194*.012) since students who have not yet developed a 3-Dimensional conception need to perform freehand sketches in order to better conceive the parts presented in isometric views.

The sustainability of the learning framework (see Table 4). The sustainability of the context can be determined by 2 variables since an implicit relation between them can be noticed (.242**.002).

Students have been asked to compare their satisfaction and familiarization versus other modules that they have been following online, during the first semester of their studies: Mathematics, Physics, Chemistry, Mechanics, Computer programming.

Table 4. Differences between the final cluster centers

\begin{tabular}{|l|c|c|}
\hline \multirow{2}{*}{} & \multicolumn{2}{|c|}{ Cluster } \\
\cline { 2 - 3 } & $\boldsymbol{1}$ & 2 \\
\hline Satisfied online CAD I vs other online modules & 8 & 9 \\
\hline Study time per week (hours) & 3 & 4 \\
\hline Study time during the week (day) & 5 & 6 \\
\hline Evaluate class notes & 3 & 4 \\
\hline Helpful the presence of cutting planes in blue in 3-dimentional views & 4 & 5 \\
\hline Dealing with knowledge deficiencies & 4 & 5 \\
\hline Classroom fatigue & 3 & 4 \\
\hline Hours/Day on PC for educational purposes & 3 & 4 \\
\hline Hours/Day on PC for attending online modules & 2 & 3 \\
\hline Number of active students at the end & 22 & 23 \\
\hline Activity MS Teams (insights) & 25 & 41 \\
\hline Total grade & 6 & 7 \\
\hline
\end{tabular}

\subsection{Cluster analysis and discussion}

A cluster analysis has been performed by employing the k-means algorithm [28, 29] (see Table 5) separating the population into two homogeneous students' groups that participate in the research sample. The variables that have been taken into consideration are the ones that are proven to be highly related to the final grade achieved on the module. The number of clusters is determined by the number of clusters formed by a dendrogram following a hierarchical clustering analysis - at the highest level of its branches. The average grade in cluster 1 is $6 / 10$ and on cluster $27 / 10$.

The first cluster represents a group of $84 / 165$ students with lower academic achievements during this semester. They are less satisfied from the online CAD I module comparing to other courses, they spend less time on their homework tasks, seem to identify their knowledge deficiencies and find the online course more exhausting.

On the other hand, the second cluster represents 81/165 students with higher academic performance. This group has managed to distinguish details that play an important role on perceiving the $3 \mathrm{D}$ objects, and more specifically the presence of cutting planes on isometrical drawings, and consider this feature extremely helpful. They tend to spend more time on their computers for educational purposes, for homework and for 
attending other courses. Their activity index on MS Teams activity is $61 \%$ higher in comparison with the first cluster, which makes this variable the most important (see Table 5).

A slight proportion analogy can be observed on the number of students forming each cluster, leaning towards a $51 \%$ of students with poorer academic performance, versus a 49\% with higher achievements (see Table 5, 6). Both clusters seem to feel fairly comfortable for the final exam and understand the necessity of sketching before CAD drawings. The number of quitting students inside their class group and the number of lectures given during this semester does not play any significant role on the clustering.

Table 5. Number of cases in clusters

\begin{tabular}{|c|c|c|}
\hline \multirow{2}{*}{ Cluster } & 1 & 84.000 \\
\cline { 2 - 3 } & 2 & 81.000 \\
\hline \multicolumn{2}{|c|}{ Valid } & 165.000 \\
\hline \multicolumn{2}{|c|}{ Missing } & .000 \\
\hline
\end{tabular}

Table 6. Case processing summary

\begin{tabular}{|l|c|c|c|}
\hline \multicolumn{2}{|c|}{} & $\mathbf{N}$ & \% \\
\hline \multirow{3}{*}{ Cases } & Valid & 141 & 85.5 \\
\cline { 2 - 4 } & Excludeda & 24 & 14.5 \\
\cline { 2 - 4 } & Total & 165 & 100.0 \\
\hline
\end{tabular}

Reliability Analysis (Cronbach's Alpha coefficient) and discussion. The questions above have been assessed in terms of reliability on the basis of Cronbach's Alpha coefficient in order to estimate the internal consistency associated with the selected values, providing a validity, and determining whether it is reasonable to interpret values that have been grouped together, dividing the sample into two homogeneous students' groups. It can be noticed from the table above that 141 out of the 165 students are included in the analysis.

The Cronbach's Alpha coefficient (see Table 7) indicates that $90 \%$ of the variance in that score can be considered as a true score variance can be interpreted, by combining those 37 questions as shown in Table 7 and 8, and therefore represents a very good to excellent reliability level ${ }^{7}$. Regarding the reliability analysis, the most significant variables from the correlation analysis have been processed, focusing on the construct of assignments.

Table 7. True score variance

\begin{tabular}{|c|c|}
\hline \multicolumn{2}{|c|}{ Reliability Statistics } \\
\hline Cronbach's Alpha & Number of Items \\
\hline 0.898 & 37 \\
\hline
\end{tabular}

${ }^{7} 0.8 \leq \alpha \leq 0.9$ 
Table 8. Cronbach's Alpha coefficient of each variable

\begin{tabular}{|c|c|c|c|}
\hline Variables (Survey Questions) & $\begin{array}{c}\text { Scale Mean } \\
\text { if Item } \\
\text { Deleted }\end{array}$ & \begin{tabular}{c|} 
Scale \\
Variance if \\
Item Deleted
\end{tabular} & $\begin{array}{l}\text { Cronbach's } \\
\text { Alpha if Item } \\
\text { Deleted }\end{array}$ \\
\hline CAD I enjoyable vs other labs & 166.79 & 290.14 & .893 \\
\hline Familiarized to MS Teams vs other modules & 166.97 & 292.81 & .895 \\
\hline Satisfied vs other modules & 162.56 & 276.15 & .891 \\
\hline Insecure about online CAD I & 167.43 & 292.80 & .896 \\
\hline Comfortable for the finals CAD I & 167.70 & 295.73 & 897 \\
\hline Affected by technical issues & 167.45 & 295.05 & 897 \\
\hline Data consumption You Tube channel videos & 166.83 & 289.70 & .896 \\
\hline Assignments' load & 167.60 & 299.01 & .897 \\
\hline Studying during the week (day) & 165.30 & 296.70 & .897 \\
\hline Satisfied with assignments grades & 167.14 & 299.55 & .897 \\
\hline Well organized CAD I & 162.61 & 280.52 & .893 \\
\hline How well tasks are assessed & 166.84 & 298.71 & .896 \\
\hline How did the theoretical part contribute on assignments? & 167.51 & 293.09 & .895 \\
\hline Tasks variety (Sketching, Quizzes, CAD) & 166.89 & 293.80 & .894 \\
\hline Evaluate module's notes & 167.54 & 291.85 & .894 \\
\hline Quizzes helped on theory & 166.84 & 295.32 & .895 \\
\hline Conceiving the meaning of planes & 166.96 & 295.68 & .896 \\
\hline Highlight of cutting planes & 166.64 & 298.89 & .896 \\
\hline Object fully perceived on tasks assigned & 166.88 & 302.16 & .898 \\
\hline Quality of videos on assignment methodology & 162.55 & 284.41 & .894 \\
\hline Clearness of image \& sound on videos & 166.96 & 299.42 & .897 \\
\hline Social media applications' skills & 166.69 & 294.33 & .894 \\
\hline Classroom fatigue & 167.50 & 281.39 & .893 \\
\hline Opportunity to express questions during online lectures & 166.57 & 296.93 & .896 \\
\hline Questions being answered & 166.78 & 292.66 & .894 \\
\hline Comments made by the instructor help understand the object & 167.77 & 294.27 & 897 \\
\hline $\begin{array}{l}\text { Did the instructor favor meeting new classmates during online } \\
\text { CAD I }\end{array}$ & 168.66 & 298.90 & .898 \\
\hline Have you noticed weaknesses & 166.56 & 297.86 & .897 \\
\hline Computer skills & 166.95 & 296.25 & .897 \\
\hline Assignments relevant to future work & 163.39 & 281.98 & .898 \\
\hline Presentation and clarity of instructions in the 15 th assignment & 167.14 & 291.54 & .895 \\
\hline 15th assignment relevant to real world tasks & 167.02 & 298.63 & .898 \\
\hline Assignments related to the real world & 167.28 & 295.42 & .896 \\
\hline Overall evaluation CAD I & 162.70 & 272.32 & .889 \\
\hline Knowledge deficiencies & 166.67 & 295.12 & .898 \\
\hline Likely to succeed in a similar future task & 167.45 & 291.95 & .894 \\
\hline
\end{tabular}

\subsection{ANOVA analysis applied on the clusters}

The most important variables derived from the clustering are the ones with Significance $<0.05$, for the clustering along with an ANOVA analysis [28, 29], that compared the differences between the individual clusters and within the individual clusters (between groups/within groups comparison) which are shown in Table 9. Because the clusters were chosen to maximize the differences between instances in various clusters, the $\mathrm{F}$ tests should only be used for descriptive purposes. Because the observed significance 
levels aren't corrected for this purpose, they can't be applied for testing the case that the cluster means are equal.

Thus, the weekly study time, the time spend on pc for academic purposes (following online courses, practicing homework and tasks) and the MS Teams activity index are variables that have a statistically significant association with the total grade and cannot be easily overpassed in future samples.

Table 9. ANOVA analysis applied on the clusters: most important variables

\begin{tabular}{|l|c|c|c|c|c|}
\hline \multirow{2}{*}{\multicolumn{1}{c|}{ Variables (Survey questions) }} & \multicolumn{2}{c|}{ Error } & \multicolumn{2}{c|}{ Sig. } \\
\cline { 2 - 5 } & Mean Square & Mean Square & df & \multicolumn{2}{c|}{} \\
\hline Study time /week & 36.234 & 1.687 & 163 & 21.476 & .000 \\
\hline Studying during the week & 15.333 & 1.083 & 163 & 14.165 & .000 \\
\hline Knowledge deficiencies & 11.932 & 1.368 & 163 & 8.723 & .004 \\
\hline Hours per day on pc for educational purposes & 9.595 & 1.069 & 163 & 8.978 & .003 \\
\hline Hours per day to attend online modules & 7.008 & 0.489 & 163 & 14.341 & .000 \\
\hline Basic software skills & .000 & .855 & 163 & .000 & .988 \\
\hline Likely to succeed in a similar future task & 2.434 & .746 & 163 & 3.264 & .073 \\
\hline Activity in MS Teams (Microsoft Insights) & 10935.709 & 39.337 & 163 & 278.002 & .000 \\
\hline Total grade & 123.502 & 3.772 & 163 & 32.744 & .000 \\
\hline
\end{tabular}

\subsection{Factor analysis and discussion}

For the variables that were found to have statistically significant correlation with the final exam student's grade, the principal component analysis algorithm is used to perform a factor analysis (PCA, and via a Varimax type of rotation) [28, 29]. The components reveal latent relationships between variables, as outlined by the comments below (Table 10). The loadings within the tables denote the highest impact that a particular variable has on the generated components. It can be assumed that the highest loadings indicate the fact that a particular variable, primarily has an impact on the component with the highest loading. The factor analysis has been applied on a total of 32 variables. The generated rotated matrix produced 11 components aiming to reveal new constructs with positive or negative impact on student's academic performance, expressed as the acquired final grade.

The first factor deals with the student's impression from the learning framework. Students who achieved higher performance on their finals, seem to enjoy the most the online CAD I, got quickly familiarized with MS Teams platform, are very satisfied with the way homework and tasks are assigned and graded, and evaluate positively the syllabus. Those students who are mostly satisfied, find online CAD I module more enjoyable than other online theoretical and laboratory courses. This general positive attitude has a positive impact to their academic performance, as, important loadings are focalized on their higher evaluations of the online course.

The second component relates to the student's engagement on the online course during this semester, and more precisely during the COVID-19 lockdown period. The daily 
time spent on their computer in order to follow online courses and work on their assignments and tasks is expressed in hours on MS Teams, which is stated in the platform's insights. The longer time they commit, the highest are their academic achievements, which reveals a rational relationship. It can be assumed that late instructors' assignment gradings is not the cause of dropouts, since students that resent this, generally belong to classes with a smaller number of quitting students.

Table 10. Factor analysis of variables with a statistically significant correlation with the student's final exam score

\begin{tabular}{|c|c|c|c|c|c|c|c|c|c|c|c|}
\hline & 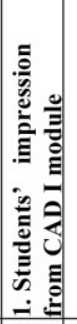 & 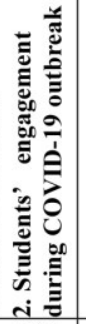 & 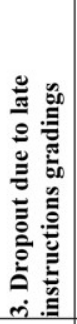 & 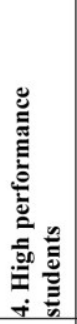 & 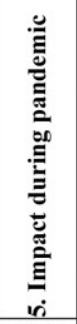 & 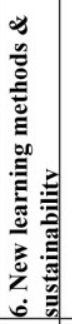 & 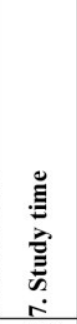 & 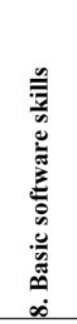 & 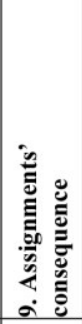 & 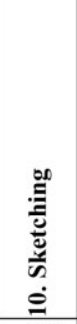 & 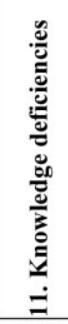 \\
\hline Enjoyable vs other labs & .715 & .241 & & & .222 & & -.182 & & & -.132 & .147 \\
\hline Familiarised to MS Teams & .734 & .145 & & & -.121 & .165 & & & -.167 & .193 & .149 \\
\hline Satisfied vs other modules & .614 & & .234 & & .131 & \begin{tabular}{|l|l}
.101 \\
\end{tabular} & & & .427 & -.195 & \\
\hline Insecurity & .174 & -.147 & .135 & & .726 & & .153 & -.161 & & .163 & .274 \\
\hline Comfortable for the finals & .111 & & .109 & & .708 & & & .127 & -.150 & -.145 & -.130 \\
\hline Technical difficulties & & -.171 & & -.203 & .155 & .113 & & -.697 & & & -.269 \\
\hline $\begin{array}{l}\text { Assignments graded \& } \\
\text { returned after }\end{array}$ & & -.123 & -.444 & .733 & & & & .203 & & & .171 \\
\hline Study time/week & & .212 & -.203 & .297 & & & .685 & & & & \\
\hline Study time during week & & .117 & & & & .169 & .777 & .265 & & & \\
\hline How well tasks are assessed & .467 & & .295 & .328 & & .256 & & .151 & .210 & .164 & -.136 \\
\hline Evaluate class notes & .392 & .320 & & & .248 & & & .121 & .118 & .386 & .135 \\
\hline $\begin{array}{l}\text { Quizzes on understanding } \\
\text { theory }\end{array}$ & .282 & .101 & -.140 & & -.227 & & -.106 & -.123 & .661 & .198 & \\
\hline Necessity of sketching & & & & & & & & & & .878 & \\
\hline Conceive planes & .236 & & & .226 & .137 & .636 & -.149 & .140 & & -.290 & .209 \\
\hline Presence of cutting planes & & & -.104 & -.130 & & .817 & .256 & & .184 & .122 & \\
\hline Enjoyable vs other theory & .758 & & & & & & & & .274 & & \\
\hline Classroom fatigue & .433 & .236 & & & .540 & & -.185 & & .276 & .126 & \\
\hline Hours/day edu purposes & & .773 & & & & .212 & & .128 & .100 & .154 & \\
\hline Hours/day follow modules & & .782 & & & -.129 & .108 & .220 & .118 & & & \\
\hline Resent late gradings & & -.357 & .460 & .237 & .159 & & -.275 & & .376 & & .188 \\
\hline Weaknesses & .145 & & & .152 & .133 & \begin{tabular}{|l|}
.124 \\
\end{tabular} & & & & & .801 \\
\hline Basic software skills & .161 & & & & .171 & .147 & & .608 & & -.151 & -.245 \\
\hline $\begin{array}{l}\text { Assignments relevant to } \\
\text { future work }\end{array}$ & & .162 & & & & .109 & .230 & .427 & .627 & & \\
\hline Succeed in future task & .265 & .278 & & .364 & .255 & .304 & & .197 & .358 & -.206 & \\
\hline Sustainability of context & & .342 & .103 & .199 & .314 & .401 & & .118 & & & -.513 \\
\hline CAD I vs other modules & .774 & -.166 & .104 & & .152 & & & & & & -.122 \\
\hline Grade Physics & .208 & & & .616 & -.168 & .222 & & -.118 & -.164 & & -.117 \\
\hline Quitting students & & & .897 & -.226 & & & & -.119 & & & \\
\hline $\mathrm{Nr}$ of lectures & & & .259 & -.782 & & .183 & & -.101 & -.155 & & -.134 \\
\hline Activity MS Teams & & .542 & & & & \begin{tabular}{|l|l|}
.102 & \\
\end{tabular} & .464 & -.302 & & -.346 & .104 \\
\hline \multicolumn{12}{|c|}{$\begin{array}{l}\text { Extraction Method: Principal Component Analysis. } \\
\text { Rotation Method: Varimax with Kaiser Normalization. }\end{array}$} \\
\hline
\end{tabular}


The fourth factor defines a construct referring to students with a higher educational potential on the online CAD I module. The characteristics that are considered important include the students' performance in the university entrance examination in physics that took place during the COVID-19 lockdown period. The higher grades are related to students finding it likely to succeed in similar tasks in the future. Other important variables revealed are the lack of knowledge deficiencies, instructors' on time assignments gradings and low number of quitting students in their teams. The number of lectures seem to have negative impact on their grades. Since the margin on the number of lectures carried out through the first semester is very small ( $\min 10$, max 11 ), it can be assumed that those 2 lectures did not cause any positive difference.

The fifth factor reveals the impact of online learning under extreme circumstances (global pandemic). The highest loading is detected on the level of insecurity towards the specific course and the final test.

The new learning methods introduced aiming to increase spatial conception have proved to be significant by validating the presence of cutting planes (values with the highest loading) in the given objects' images. Higher performance students have conceived the meaning of planes and consider the context sustainable in face-to-face learning. Students who haven't been able to develop their spatial conception throughout the virtual CAD I class don't find it sustainable ${ }^{8}$, when returning to normality in a real class environment. The importance of weekly involvement on assignments and tasks along with the MS Teams insights ratio is revealed while students resent on instructors' late gradings has a negative impact on the final grade.

The importance of software skills previously acquired in MS office applications, and the general feeling of competency related to computer skills can be noticed. Assignments coherence as revealed through the contribution of quizzes on understanding the theoretical part along with the relevance of the assignments with future work constitutes another latent factor. Students who understand the contribution of quizzes expand their conception to more general cognitive features.

The tenth factor brings to light the necessity of sketching, scaled free-handed drawing which is one of the basic skills acquired through the online CAD I module. This factor is not related with any other variable, but still proves an actual relation with the final exam.

\section{Conclusions}

Taking advantage of an unprecedented adversity in the global educational community, student performance data revealing their transition from high school to higher education through the COVID-19 pandemic were digitally collected and processed through statistical analysis. Since a new educational concept has been implemented, new factors are emerging that may affect students' academic performance. While educators' empirical data on face-to-face learning environments could predict at-risk students, in the absence of a real classroom, important information may be overlooked [30]. Course content reform in a new virtual environment was tested by introducing

\footnotetext{
${ }^{8}$ Sustainability of the online learning framework, chapter 3.4
} 
novelties in the educational procedure to improve spatial design, which proved to be effective and sustainable for similar future learning circumstances.

The above provided more in-depth information for each student, and significant relationships were revealed regarding the students' transition from high school to graduate level, as well as their level of understanding of more complex topics, such as geometric features. Based on the above results, the main factors influencing students' academic performance include: Activity in MS Teams (Microsoft Insights), Appreciation in relation to other lab and theory modules, Study time during the week, Organization, Presence of cutting planes in three-dimensional views, fully perceived object on assigned tasks, Fatigue in class, Likelihood of succeeding in a similar future task, Quality of videos in homework methodology, Comfort for finals. Considerable evidence of the effectiveness of the online learning framework that was incorporated, showed a positive impact on their learning paths.

Using the results of this research, several factors were revealed to have a significant relationship with students' academic performance during COVID-19 restrictions. Since not all revealed factors have the same weight of significance, the presented methodology can be applied to the first semester of the next academic year, in order to test the weight of each variable and arise more accurate conclusions. The results of the analysis can be used as a function proxy to predict student performance under similar future circumstances.

\section{Acknowledgment}

The authors would like to thank the University of Western Attica for financial support for this research.

\section{$7 \quad$ References}

[1] Whittle, C., Tiwari, S., Yan, S. and Williams, J. (2020), Emergency remote teaching environment: a conceptual framework for responsive online teaching in crises, Information and Learning Sciences, 121(5/6): 311-319. https://doi.org/10.1108/ils-04-2020-0099

[2] Hodges, C., Moore, S., Lockee, B., Trust, T. and Bond, A. (2020). The Difference Between Emergency Remote Teaching and Online Learning, Educausereview: https://er.educause .edu/articles/2020/3/the-difference-between-emergency-remote-teaching-and-online-learning.

[3] Jacques, S., Ouahabi, A., Lequeu, T. (2020). Remote Knowledge Acquisition and Assessment During the COVID-19 Pandemic. International Journal of Engineering Pedagogy, 10(6):120-138. https://doi.org/10.3991/ijep.v10i6.16205

[4] Iqbal, Z. Qadir, J. Mian, A. Kamiran, F. Machine Learning Based Student Grade Prediction: A Case Study, Cornell University, 2017, USA, pp. 1-22

[5] Lischer, S., Safi, N. \& Dickson, C. (2021). Remote learning and students' mental health during the COVID-19 pandemic: A mixed-method enquiry. Prospects, 1-11. https://doi.org/ 10.1007/s11125-020-09530-w

[6] Callaghan, M.J., McShane, N., Eguiluz, A.G., Savin-Baden, M. (2018). Extending the Activity Theory Based Model for Serious Games Design in Engineering to Integrate Analytics. 
Paper-Analysis of Engineering Student Data in Online Higher Education During the COVID-19...

International Journal of Engineering Pedagogy, 8:109-126. https://doi.org/10.3991/ijep. $\underline{\mathrm{v} 8 \mathrm{i} 1.8087}$

[7] Hasiloglu, M.A., Kunduraci, A. (2018). A Research Study on Identifying the Correlation between Fourth Graders' Attitudes and Behaviors toward the Environment, International Education Studies, 11: 60-65. https://doi.org/10.5539/ies.v11n6p60

[8] Yi, B. \& Wang, Y., Zhang, D., Zhou, X., Shu, J., Zhang, Z., Lv, Y. (2017). Learning Analytics-Based Evaluation Mode for Blended Learning and Its Applications. International Symposium on Educational Technology, 2017, China, pp. 147-149. https://doi.org/10.1109/ iset.2017.42

[9] Li, X. Xie, L. and Wang, H. Grade Prediction in MOOCs, IEEE Intl Conference on Computational Science and Engineering (CSE) and IEEE Intl Conference on Embedded and Ubiquitous Computing (EUC) and 15th Intl Symposium on Distributed Computing and Applications for Business Engineering (DCABES), 2016, France, pp. 386-392. https://doi.org/ 10.1109/cse-euc-dcabes.2016.153

[10] Ismail H., Balkhouche B., Harous S. (2020). Mining Web Analytics Data for Information Wikis to Evaluate Informal Learning. International Journal of Engineering Pedagogy, 10: 125-149. https://doi.org/10.3991/ijep.v10i1.11713

[11] Shorfuzzaman, M., Shamim Hossainbc, M., Nazir, A., Muhammadd, G. and Alamri, A. (2018). Harnessing the power of big data analytics in the cloud to support learning analytics in mobile learning environment. Computers in Human Behavior, 92: 578-588. https://doi.org/10.1016/j.chb.2018.07.002

[12] Gašević, D., Kovanović, V. and Joksimović, S. (2017). Piecing the learning analytics puzzle: a consolidated model of a field of research and practice. Learning: Research and Practice, 3(1):63-78. https://doi.org/10.1080/23735082.2017.1286142

[13] Troussas C., Krouska A., Virvou M. (2020) Using a Multi Module Model for Learning Analytics to Predict Learners' Cognitive States and Provide Tailored Learning Pathways and Assessment. In: Virvou M., Alepis E., Tsihrintzis G., Jain L. (eds) Machine Learning Paradigms. Intelligent Systems Reference Library, vol 158. Springer, Cham. https://doi.org/10. 1007/978-3-030-13743-4 2

[14] Wong, Billy. (2017). Learning analytics in higher education: an analysis of case studies. Asian Association of Open Universities Journal. 12:21-40.

[15] Nunn, S., Avella, J.T., Kanai, T. and Kebritchi, M. (2016). Learning analytics methods, benefits, and challenges in higher education: a systematic literature review. Online Learning, 20(2):13-29. https://doi.org/10.24059/olj.v20i2.790

[16] Ihantola, P., Vihavainen, A., Ahadi, A., Butler, M., Börstler, J., Edwards, S.H., Isohanni, E., Korhonen, A., Petersen, A., Rivers, K., Rubio, M.Á., Sheard, J., Skupas, B., Spacco, J., Szabo, C. and Toll, D. Educational data mining and learning analytics in programming: literature review and case studies. The 20th Annual Conference on Innovation and Technology in Computer Science Education - Working Group Reports, ACM, 2015, New York, NY, pp. 41-63. https://doi.org/10.1145/2858796.2858798

[17] Rechkoski, L., Mitreski, Z. Different Statistical Methods in Predicting Student Course Enrollment, Proceedings of the 14th International Conference for Informatics and Information Technology, 2017, Mavrovo, Macedonia, pp. 4-9.

[18] Westrick, P., Marini, J., Young, L. Ng, H., Shmueli, D., Shaw, E. (2019). Validity of the SAT ${ }^{\circledR}$ for Predicting First-Year Grades and Retention to the Second Year. 2019 College Board, Technical report.

[19] Gil, P. \& Martins, S., Moro, S., Costa (2021). A data-driven approach to predict first-year students' academic success in higher education institutions. Education and Information Technologies, 26:2165-2190. https://doi.org/10.1007/s10639-020-10346-6 
Paper-Analysis of Engineering Student Data in Online Higher Education During the COVID-19...

[20] Kanetaki, Z., Stergiou, C., Bekas, G., \& Kanetaki, E. Machine Learning and Statistical Analysis applied on Mechanical Engineering CAD course: A Case Study During ERTE Pahse in the Context of Higher Education. $4^{\text {th }}$ IEEE International Symposium on Multidisciplinary Studies and Innovative Technologies, 2020, pp. 1-13. https://doi.org/10.1109/ismsit50672. 2020.9254924

[21] Fewella, L., Khodeir, L., Suidan, A. (2021). Impact of Integrated E-learning: Traditional Approach to Teaching Engineering Perspective Courses. International Journal of Engineering Pedagogy, 11:82-101. https://doi.org/10.3991/ijep.v11i2.17777

[22] Tordai, Z., Holik, I. (2018). Student's Characteristics as a Basis for Competency Development in Engineering Informatics Education. International Journal of Engineering Pedagogy, 8:32-42. https://doi.org/10.3991/ijep.v8i4.8133

[23] Safsouf, Y. Mansouri, K. and Poirier, F. Smart learning environment, measure online student satisfaction: a case study in the context of higher education in Morocco, International Conference on Electrical and Information Technologies (ICEIT), 2020, Rabat, Morocco, pp. 15. https://doi.org/10.1109/iceit48248.2020.9113189

[24] El Guabassi, I. \& Bousalem, Z. \& Rim, M. \& Qazdar, A. (2021). A Recommender System for Predicting Students' Admission to a Graduate Program using Machine Learning Algorithms. International Journal of Online and Biomedical Engineering, 17:135-147. https://doi. org/10.3991/ijoe.v17i02.20049

[25] Giannakas, F., Troussas, C., Voyiatzis, I., Sgouropoulou, C. (2021). A deep learning classification framework for early prediction of team-based academic performance, Applied Soft Computing, 106:107355, https://doi.org/10.1016/j.asoc.2021.107355

[26] Sharov, S. Vorovka, M. \& Sharova, T., Zemlianska, A. (2021). The Impact of Social Networks on the Development of Students' Social Competence. International Journal of Engineering Pedagogy (iJEP). 11:84-98. https://doi.org/10.3991/ijep.v11i3.20491

[27] Cheng, S.Y. Wang, C. Shen, A. \& Chang, S-C. (2020). How to Safely Reopen Colleges and Universities During COVID-19: Experiences from Taiwan. Annals of Internal Medicine, 16. https://doi.org/10.7326/m20-2927

[28] Bruce, A., Bruce, P.C., Gedeck P. (2017). Practical Statistics for Data Scientists: 50+ Essential Concepts Using R and Python. O' Reilly.

[29] Shrestha, N. (2021). Factor Analysis as a Tool for Survey Analysis. American Journal of Applied Mathematics and Statistics. 9:4-11.

[30] Daemi, M.N., Tahriri, A., Zafarghandi, A.M. (2017). The Relationship between Classroom Environment and EFL Learners' Academic Self-Efficacy. International Journal of Education \& Literacy Studies, 5:16-23. https://doi.org/10.7575/aiac.ijels.v.5n.4p.16

\section{Authors}

Zoe Kanetaki is a Lecturer in the Department of Mechanical Engineering, University of West Attica. She received a degree in Architecture from E.S.A. and a M.Sc. degree in Urbanism and Regional Planning from NTUA. Her research interests include online learning, data analysis, engineering education and CAD.

Constantinos Stergiou is Professor and Head of the Mechanical Engineering Department at the University of West Attica. He received his degree in Mechanical Engineering from NTUA, Greece and his Ph.D. from Technische Universität Darmstadt. His research interests lie in the field of Engineering Design, CAD/CAM/CAE and Additive Manufacturing (email: stergiou@uniwa.gr). 
Georgios Bekas holds a PhD in Civil and Structural Engineering. His research interests include Operations Research, Machine Learning, and optimization of Civil and Energy Engineering works (email: gb331984@googlemail.com).

Christos Troussas is Adjunct Lecturer in the Department of Informatics and Computer Engineering, University of West Attica, Greece. He received the B.Sc., M.Sc., and Ph.D. degrees in Informatics from the Department of Informatics, University of Piraeus, Greece. His current research interests include software engineering, multiagent systems, adaptive HCI, and artificial intelligence (email: ctrouss@uniwa.gr).

Cleo Sgouropoulou is Vice Rector of the University of West Attica, Greece and Professor in the Department of Informatics and Computer Engineering of the same University. She received the B.Sc. and Ph.D. degrees in electrical and computer engineering from the Department of Electrical and Computer Engineering, NTUA, Greece. Her research interests include artificial intelligence in education and software engineering (email: csgouro@uniwa.gr).

Article submitted 2021-04-13. Resubmitted 2021-07-13. Final acceptance 2021-07-20. Final version published as submitted by the authors. 